\title{
Diagnostic and Therapeutic Challenges in The Management of Acute Massive Overt Bleeding of Jejunal Gastrointestinal Stromal Tumours: Case Series
}

\section{SATISH SUBBIAH NAGARAJ}

PGIMER: Post Graduate Institute of Medical Education and Research https://orcid.org/0000-00032363-982X

\section{Sriram Deivasigamani}

PGIMER: Post Graduate Institute of Medical Education and Research

Amresh Aruni

PGIMER: Post Graduate Institute of Medical Education and Research Hemanth Kumar ( $\square$ hemanthkr21@gmail.com )

PGIMER: Post Graduate Institute of Medical Education and Research

\section{Anurag Sachan}

PGIMER: Post Graduate Institute of Medical Education and Research

\section{Jayanta Samanta}

PGIMER: Post Graduate Institute of Medical Education and Research

\section{Amanjit Bal}

PGIMER: Post Graduate Institute of Medical Education and Research

\section{Research Article}

Keywords: Gastrointestinal Stromal Tumour, Jejunum, Bleeding, Computed Tomography, Surgery

Posted Date: March 18th, 2021

DOl: https://doi.org/10.21203/rs.3.rs-307477/v1

License: (9) This work is licensed under a Creative Commons Attribution 4.0 International License. Read Full License 


\section{Abstract}

\section{Introduction:}

Jejunal Gastro-Intestinal Stromal Tumours (GIST) are rare mesenchymal tumours. Acute massive overt bleeding from jejunal GIST are very rare and poses both diagnostic and therapeutic challenges in emergent conditions.

\section{Methods}

A case series with retrospective analysis of prospectively maintained database of patients presenting with acute massive overt bleeding secondary to histologically proven jejunal GIST was done. Clinical characteristics, endoscopic and imaging diagnostic features, histological findings, surgical procedures and outcomes in these patients were studied.

\section{Results}

Three patients were included in this case series. Mean age of presentation was 49.0 years with two male and one female patient. All three patients presented with melena and hemodynamic instability, resuscitated with adequate blood transfusions. Routine endoscopic assessment were inconclusive. Multiphasic Computed Tomographic Angiography (CTA) revealed hypodense hypervascular mass in jejunum in all three patients. One patient was unresponsive to blood transfusion and underwent emergency exploratory laparotomy. One patient underwent laparoscopic resection and reconstruction. Mean length of hospital stay was 5.3 days. Histopathological examination confirmed Jejunal GIST in all three patients with microscopically negative resection margins. Two patients were disease free till 18 months follow up and the one patient lost to follow up after 1 year.

\section{Conclusion}

Multiphasic CTA is a single step diagnostic tool for localisation of bleed and assessment of tumour characteristics in emergent conditions. Surgical resection is the mainstay of treatment for both control of bleed and to provide oncologically clear resection margins.

\section{Introduction}

Gastro-Intestinal Stromal Tumours (GIST) rarely involves jejunum which constitutes $10 \%$ of all GIST and $0.04 \%$ of all Small Bowel (SB) neoplasm[1,2]. The diagnosis of jejunal GIST is usually delayed due to its relative low incidence, variable non-specific symptoms, inaccessibility by routine endoscopic techniques and wide range of radiological appearances [3]. Bleeding is the most common presenting complaint (30$40 \%$ ) and accounts for less than $5 \%$ of all Gastro-Intestinal (GI) bleed[3,4]. Rarely jejunal GIST can present 
with acute massive overt GI bleed resulting in hemodynamic instability[5]. The patient status, magnitude of bleed, location of tumour, tumour characteristics and the availability of resources mandate the management of bleeding lesions with best possible oncological outcomes[6]. We are presenting a series of three cases of Jejunal GIST with symptoms of acute massive overt GI bleed and discuss the diagnostic and therapeutic oncological goals of its management under emergent conditions.

\section{Methods}

The study is a case series with a retrospective analysis of prospectively maintained database of nonconsecutive patients presenting to emergency surgical department of Postgraduate Institute of Medical Education and Research, Chandigarh, India with acute massive overt GI bleed with hemodynamic instability secondary to histologically proven Jejunal GIST during the period of July 2017 to June 2020. A total of three patients met the above said criteria and were included in the study. We describe the clinical characteristics, endoscopic and imaging diagnostic features, histological findings, surgical procedures and outcomes in these patients.

The data collected included patient demographics, symptomatology, abdominal signs, anatomical localisation, tumour characteristics, laboratory findings, surgical procedure performed, pathological findings, immunohistochemical (IHC) analysis, length of hospital stay and Intra and post-operative complications. Pre-operative diagnosis, evaluation of tumour characteristics were performed using Upper GI (UGI) endoscopy, colonoscopy, Multiphasic Computed Tomographic Angiography (CTA) of abdomen. Patients were resuscitated with adequate blood transfusions. Hemodynamically unstable patients were subjected to emergency laparotomy and stable patients were operated electively in an early date in view of ongoing active chronic bleed. The procedure involved both open and laparoscopic techniques. Intraoperatively jejunal tumours were resected carefully with adequate tumour margins and without tumour capsule breach. Pathological specimens were examined for tumour site, size, margins, serosal and mucosal breach. Histologically analysed for tumour subtype, nature, mitotic rate, tumour necrosis, lymphovascular invasion and tumour grade. $\mathrm{IHC}$ analysis was performed using markers such as $\mathrm{Ki} 67 \%$, CD117, c-KIT, DOG1, S-100 protein. Data were reported as nominal, ordinal, discrete and continuous variables. All the patients were followed up with length of hospital stay, routine visits initially 15 days after hospital discharge and then at intervals of 3 months up to 2 years with clinical examinations and CT.

A literature review was performed for previous publications on Pub Med and Google Scholar database including terms 'Jejunal GIST', 'GI bleed', 'Endoscopy' and 'Surgery'. The study has been reported in line with the PROCESS guidelines [7].

\section{Results}

The case details have been summarised in Table 1. A total of three patients, two males and one female with mean age of 49.0 years (range 38-62 years) were studied. All three patients had significant history of 
melena ranging from 2 days to 3 years in duration. None of the patients had hematemesis, vomiting, pain abdomen and sensation of abdominal lump. Two of these patients had similar past history of melena 1 and 2 years back with inconclusive diagnosis, treated by blood transfusions. These two patients had acute episode of melena since 2 days and 4 months and presented to surgical emergency with transient hypotension stabilised with blood transfusions. One of these patient was unresponsive to blood transfusions and was subjected to emergency laparotomy. None of these patients had significant abdominal signs and all three patients had melenic stools in digital rectal examination. The mean haemoglobin $(\mathrm{Hb})$ concentration was $8.4 \mathrm{~g} / \mathrm{dL}$ (range 5.4- 10.7) among which the patient with hemodynamic instability had $\mathrm{Hb}$ drop to $3.9 \mathrm{~g} / \mathrm{dL}$. UGI endoscopy and colonoscopy were normal among all the three patients provoking a diagnostic dilemma. Multiphasic CTA revealed hypervascular hypodense mass in jejunum in all three patients with mean size of $3.8 \mathrm{~cm}$ in max dimension (range 3.1$5.0 \mathrm{~cm}$ ) without any active contrast extravasation (Fig.1). The indication for surgery in all three patients was for control of bleed and curative oncological resection. One patient underwent laparoscopic resection and intracorporeal bowel anastomosis and other two patients underwent open exploratory laparotomy with resection of jejunal mass with adequate margins and end to end bowel anastomosis (Fig.2). Two patients had jejunal mass $20 \mathrm{~cm}$ distal to duodenojejunal (DJ) flexure and one patient with $4 \mathrm{~cm}$ distal to DJ flexure. Intraoperative cut-section of specimen revealed mucosal ulcerations in two patients who had open exploratory laparotomy (Fig.3). Postoperative period was uneventful in two patients. One patient who had hemodynamic instability preoperatively had postoperative ileus relieved conservatively in 3 days. The mean length of hospital stay was 5.3 days (range 4 to 8 days). One patient who underwent laparoscopic resection had the lowest length of hospital stay of 4 days. Histopathological and IHC analysis were performed according to Fletcher criteria and confirmed jejunal GIST type in all three cases (Fig.4\&5). The mean tumour size was $3.83 \mathrm{~cm}$ in maximum dimension (range $2.5-5.0 \mathrm{~cm}$ ), which was in accordance to radiological findings. High grade GIST, low grade GIST and benign GIST was identified in each patient. All the lesions had microscopically negative resection margins with mucosal breach and no serosal capsular breach. Mucosal breach must have been the reason for acute massive bleed in all these submucosal GIST lesions. The high grade GIST patient was started on oral Imatinib $400 \mathrm{mg}$ daily and followed up. Two patients had 18 months of follow up and the other was lost for follow up after 1 year and all were disease free until then.

\section{Discussion}

Jejunal GIST (60-70\%) are the most common small bowel GIST followed by ileum and duodenum[1, 3]. The mean age of presentation of jejunal GIST is 56 years similar to that of our case series. Jejunal GIST are symptomatic in more than $80-90 \%$ patients, which may present as either mostly insidious slow bleed or rarely acute massive haemorrhage $[3,8,9]$. In a study by Constantin et al, haemorrhagic shock was seen in $6.4 \%$ of patients of jejunal GIST[10]. Clinically, GI bleed associated with jejunal GIST usually arises from the ulcerated or necrotic component of the tumour. Hence, it may present commonly as intraluminal bleed and rarely as intra-peritoneal rupture bleed. Intraluminal bleed is usually due to the compression, ischemia, or infiltration of overlying mucosa by these highly vascular sub-mucosal layer 
tumours[11, 12]. Intra-peritoneal tumour rupture was seen in $0.11 \%(3 / 27)$ patients of SB GIST in a study by Sorour et al [12]. In our study all three patients presented with intra-luminal bleed, among which the patient with hemodynamic instability had tumour arising from mesenteric border. Retrospectively, we realized and assumed that the magnitude of bleed may depend upon the location along mesenteric border with direct mesenteric feeding vessels. Stromal collagen is minimal in most GISTs, but delicate, thin-walled vessels may be prominent, making stromal haemorrhage a common feature of these tumours[13]

\section{Diagnostic Challenges}

The diagnosis of a lesion in small bowel is determined by its location, assessment of its characteristic features and confirmation of diagnosis together by clinico-radiological, endoscopic and pathological studies. However a massively bleeding GIST does not provide time for a complete evaluation and optimised treatment plan. Usually the surgeon is faced with challenging decision of whether to operate promptly or to localize and control the source of bleed non-operatively. This mandates a dynamic multidisciplinary approach that directs diagnostic and therapeutic priorities appropriately. Lack of exchange of clinical information between the multidisciplinary team impacts the long term prognosis of the patient with acute massive GI bleed. Diagnostic modalities are wisely chosen for the field of interest to provide the most probable diagnosis in short duration of time.

\section{Endoscopy}

Jejunal GIST are inaccessible by routine UGI endoscopy and colonoscopy and are termed as 'dark continent' of small bowel due to its intra-peritoneal location, excess mobility and long length [3]. Recent advances in endoscopy such as Video Capsule Endoscopy (VCE), single balloon (SBE), double balloon (DBE) and spiral enteroscopy (SE) have made jejunal lesions accessible for both diagnostic and therapeutic indications. However, its use is recommended in chronic stable or mild to moderate suspected bleeding lesions [4]. Hence its use in acute massive overt bleeding is doubtful. Even if used to achieve haemostasis by techniques like haemoclip, laser therapy and argon plasma coagulation, it can be used as bridging procedure by temporary bleeding control followed by definitive surgery[4]. These techniques though available, was not used in view of acute massive overt bleeding of patients in our study.

\section{Radiographic Studies}

Recent advances in cross sectional imaging such as multiphasic CTA has brought considerable changes in the management of acute GI bleed. Multiphasic CTA is strongly recommended by recent guidelines as the investigation of choice in acute massive overt GI bleed in hemodynamically stable patients[4, 13$]$. It has an accuracy of $100 \%$ in localisation of bleed at a sensitivity of $85 \%$ to detect bleeding at rates of $0.3 \mathrm{ml} / \mathrm{min}$. Additionally multiphasic enhancement panel helps simultaneous assessment of the tumour characteristics, level of exophytic component and adhesion to adjacent structures with faster acquisition rates for adequate surgical planning[9, 13]. Multiphasic CTA has been used as the first line investigation in our series. The importance of use of multiphasic CTA in acute massively bleeding jejunal GIST has 
been seen in a study by daldoul et al[13]. However, CTA has limitations such as to detect the contrast extravasation, the patient must be actively bleeding at the time of scan and increases the risk of renal complications $[4,9]$.

Conventional angiography (CA) has been recommended strongly to be performed in hemodynamically unstable patients with acute massive overt GI bleed requiring more than five blood transfusions[4]. An additional advantage of $\mathrm{CA}$ is the ability to perform therapeutic intervention with super selective transarterial embolization at the time of diagnosis with the bleeding rates of $0.5-1.0 \mathrm{ml} / \mathrm{min}$. Studies have shown an overall clinical success rate of $95 \%$ and above with CA in active bleed $[4,14]$. It is used as bridge to surgery in achieving haemostasis and size reduction facilitating limited resection in metastatic GIST. The possible adverse effects of this procedure include bowel infarction (4\%) and procedure related complications such as arterial dissection, non-target embolization, renal failure and catheter site infection and hematoma up to $10 \%[15,16]$.

There is a considerable controversy in the use of ${ }^{99 \mathrm{~m}}$ Tc-labelled RBC scintigraphy for acute overt GI bleed. It has been recommended in uncertainty of active bleed and to guide timing of angiography[4].

\section{Therapeutic challenges}

Surgical resection remains the main stay of treatment of non-metastatic GIST $[3,8,17]$. The two main objectives in surgical management of acute massive jejunal GIST bleed is the control of bleed and to provide an oncologically clear resection margins. Control of bleed initially begins with adequate resuscitation. Volume replacement is the cornerstone of resuscitation, but non-targeted aggressive fluid resuscitation must be avoided to allow clot formation and to prevent increased bleeding. Coagulopathy must be corrected and hypothermia avoided. Any medications such as antiplatelet and anticoagulants are immediately stopped[18]. In our study all three patients had haemorrhagic shock at presentation and two patients responded to resuscitation.

The oncological principle mandates R0 resection without tumour capsular breach[17, 19]. Surgical procedure may include local excision and segmental resection based on the size of tumour[8]. Adjacent organs adherent to the mass should be resected en bloc with the tumour, in order to avoid capsule rupture and intra-abdominal spillage with reconstruction to maintain $\mathrm{Gl}$ continuity is recommended, whenever feasible[20]. In a study by Wu et al showed that complete tumour resection is an important predictor for patient survival with a significantly increased median survival of 123.3 months compared with 12.0 months for those who had incomplete surgical resection. SB GIST has an additional risk of early recurrence. In the same study, $51.8 \%$ patients had recurrence who underwent curative resection within a median time of recurrence of 20.5 months[8]. In a study by Liu et al, GI bleeding caused by GIST was identified as an independent risk factor for recurrence and death $(p=0.039)$. This study also showed both disease free survival $(p=0.0002)$ and overall survival $(p=0.023)$ were shorter for patients with GIST bleed[21]. Routine lymphadenectomy is usually not required as jejunal GIST rarely metastasize to local or 
regional lymph nodes $[17,19]$. All our patients had complete R0 segmental resection without tumour capsule breach.

Surgical techniques include open and laparoscopic resection. One patients in our study underwent laparoscopic resection and other two patients an open exploratory laparotomy. In patients who have large GIST a laparoscopic surgical approach is clearly discouraged due to increased risk of intra-abdominal seeding[22]. Ihn et al reported that laparoscopic resection for GIST of the small bowel of $<10 \mathrm{~cm}$ in diameter had a more favourable short-term postoperative outcome while achieving comparable oncologic results, when compared with open surgery[23]. This study has several limitations such being a case series of three cases, single centre, retrospective study and potential confounding factors were not studied. Proper management mandates recommendation guidelines from large scale randomised control trials and meta-analysis.

\section{Conclusion}

Acute massive overt bleed of jejunal GIST is very rare entity. High suspicion and anticipation is mandated for treating surgeons. Multiphasic CTA should be considered as single step process for diagnosis of bleed and tumour characteristics in emergent conditions. Surgical resection is the mainstay of treatment for both control of bleed and to provide oncologically clear resection margins. Jejunal GIST has a high propensity for recurrence. GIST bleed is an independent risk factor for poor prognosis. Regular close follow up is recommended for jejunal GIST bleed[19, 20, 22].

\section{Declarations}

Funding: No funding was received for conducting this study

Conflicts of Interest: The authors have no conflicts of interest to declare that are relevant to the content of this article

\section{Author's Contributions:}

Satish Subbiah Nagaraj and Hemanth Kumar contributed to the study conception and design.

Material preparation, data collection, analysis and first draft of the manuscript were written by Satish Subbiah Nagaraj, Sriram Deivasigamani, Amresh Aruni, Anurag Sachan

Manuscript review, editing, supervision and final approval was done by Satish Subbiah Nagaraj, Hemanth Kumar, Jayanta Samata and Amanjit Bal

Ethical approval: All procedures performed in this study involving human participants were in accordance with the ethical standards of the institutional and/or national research committee and with the 1964 Helsinki Declaration and its later amendments or comparable ethical standards. 
Informed Consent: Written informed consent for the paper to be published (including images, case history, and data) was obtained from the patient/guardian for publication of this paper, including accompanying images.

\section{References}

1. Fletcher CDM, Berman JJ, Corless C, Gorstein F, Lasota J, Longley BJ, et al. Diagnosis of gastrointestinal stromal tumors: A consensus approach. Hum Pathol. 2002;33:459-65.

2. Roy SD, Khan D, De KK, De U. Spontaneous perforation of jejunal gastrintestinal stromal tumour (gist). Case report and review of literature. World J Emerg Surg. 2012;7:2-5.

3. Zhou L, Liao Y, Wu J, Yang J, Zhang H, Wang X, et al. Small bowel gastrointestinal stromal tumor: A retrospective study of 32 cases at a single center and review of the literature. Ther Clin Risk Manag. 2018;14:1467-81.

4. Gerson LB, Fidler JL, Cave DR, Leighton JA. ACG Clinical Guideline: Diagnosis and Management of Small Bowel Bleeding. Am J Gastroenterol [Internet]. Nature Publishing Group; 2015;110:1265-87. Available from: http://dx.doi.org/10.1038/ajg.2015.246

5. Thanapal MR, Hussein H, Azizi ZA. Bleeding jejunal GIST: An uncommon cause of gastrointestinal bleeding. Med J Malaysia. 2015;70:31-2.

6. Krishnamurthy G, Singh H, Sharma V, Savlania A, Vasishta RK. Therapeutic Challenges in the Management of Bleeding Duodenal Gastrointestinal Stromal Tumor: a Case Report and Review of Literature. J Gastrointest Cancer. Journal of Gastrointestinal Cancer; 2019;50:170-4.

7. Agha RA, Borrelli MR, Farwana R, Koshy K, Fowler AJ, Orgill DP. The PROCESS 2018 statement: Updating Consensus Preferred Reporting Of CasE Series in Surgery (PROCESS) guidelines. Int J Surg. Elsevier Ltd; 2018;60:279-82.

8. Wu TJ, Lee LY, Yeh CN, Wu PY, Chao TC, Hwang TL, et al. Surgical treatment and prognostic analysis for gastrointestinal stromal tumors (GISTs) of the small intestine: Before the era of imatinib mesylate. BMC Gastroenterol. 2006;6:1-8.

9. Baheti AD, Shinagare AB, O’Neill AC, Krajewski KM, Hornick JL, George S, et al. MDCT and clinicopathological features of small bowel gastrointestinal stromal tumours in 102 patients: A single institute experience. $\mathrm{Br} \mathrm{J}$ Radiol. 2015;88.

10. Constantin VD, Socea B, Popa F, Carâp AC, Popescu G, Vlădescu T, et al. A histopathological and immunohistochemical approach of surgical emergencies of GIST. An interdisciplinary study. Rom J Morphol Embryol. 2014;55:619-27.

11. Gunjan D, Sharma V, Rana SS, Bhasin DK. Small bowel bleeding: A comprehensive review [Internet]. Gastroenterol. Rep. Oxford University Press; 2014 [cited 2021 Mar 1]. p. 262-72. Available from: https://pubmed.ncbi.nlm.nih.gov/24874805/

12. Sorour MA, Kassem MI, Ghazal AEHA, El-Riwini MT, Abu Nasr A. Gastrointestinal stromal tumors (GIST) related emergencies. Int J Surg [Internet]. Elsevier Ltd; 2014;12:269-80. Available from: 
http://dx.doi.org/10.1016/j.ijsu.2014.02.004

13. Daldoul S, Moussi A, Triki W, Baraket RB, Zaouche A. Jejunal GIST causing acute massive gastrointestinal bleeding: Role of multidetector row helical CT in the preoperative diagnosis and management. Arab J Gastroenterol [Internet]. Arab Journal of Gastroenterology; 2012;13:153-7. Available from: http://dx.doi.org/10.1016/j.ajg.2012.08.005

14. Weldon DT, Burke SJ, Sun S, Mimura H, Golzarian J. Interventional management of lower gastrointestinal bleeding [Internet]. Eur. Radiol. Eur Radiol; 2008 [cited 2021 Mar 1]. p. 857-67. Available from: https://pubmed.ncbi.nlm.nih.gov/18185932/

15. Beddy P, McGrath A, Reynolds J V., Ryan JMF. Primary Embolization of a Symptomatic Gastrointestinal Stromal Tumor [Internet]. J. Vasc. Interv. Radiol. Elsevier; 2009 [cited 2021 Mar 1]. p. 1099-101. Available from: http://www.jvir.org/article/S105104430900520X/fulltext

16. Kurihara N, Kikuchi K, Tanabe M, Kumamoto Y, Tsuyuki A, Fujishiro Y, et al. Partial resection of the second portion of the duodenum for gastrointestinal stromal tumor after effective transarterial embolization. Int J Clin Oncol [Internet]. Springer; 2005 [cited 2021 Mar 1];10:433-7. Available from: https://link.springer.com/article/10.1007/s10147-005-0503-z

17. Kang YK, Kang HJ, Kim KM, Sohn T, Choi D, Ryu MH, et al. Clinical practice guideline for accurate diagnosis and effective treatment of gastrointestinal stromal tumor in Korea. Cancer Res Treat [Internet]. Korean Cancer Association; 2012 [cited 2021 Mar 1];44:85-96. Available from: /pmc/articles/PMC3394868/

18. Kiliç YA, Konan A, Kaynaroğlu V. Resuscitation and monitoring in gastrointestinal bleeding. Eur J Trauma Emerg Surg. 2011;37:329-37.

19. Koo DH, Ryu MH, Kim KM, Yang HK, Sawaki A, Hirota S, et al. Asian consensus guidelines for the diagnosis and management of gastrointestinal stromal tumor. Cancer Res Treat [Internet]. Korean Cancer Association; 2016 [cited 2021 Mar 1];48:1155-66. Available from: https://pubmed.ncbi.nlm.nih.gov/27384163/

20. Blay JY, Bonvalot S, Casali P, Choi H, Debiec-Richter M, Dei Tos AP, et al. Consensus meeting for the management of gastrointestinal stromal tumors. Report of the GIST Consensus Conference of 20-21 March 2004, under the auspices of ESMO. Ann Oncol [Internet]. Ann Oncol; 2005 [cited 2021 Mar 1]. p. 566-78. Available from: https://pubmed.ncbi.nlm.nih.gov/15781488/

21. Liu Q, Li Y, Dong M, Kong F, Dong Q. Gastrointestinal Bleeding Is an Independent Risk Factor for Poor Prognosis in GIST Patients. Biomed Res Int. Hindawi Limited; 2017;2017.

22. Gastrointestinal stromal tumours: ESMO Clinical Practice Guidelines for diagnosis, treatment and follow-up. Ann Oncol [Internet]. Oxford University Press; 2014 [cited 2021 Mar 1];25:iii21-6. Available from: https://pubmed.ncbi.nlm.nih.gov/25210085/

23. Ihn K, Hyung WJ, Kim H II, An JY, Kim JW, Cheong JH, et al. Treatment results of small intestinal gastrointestinal stromal tumors less than $10 \mathrm{~cm}$ in diameter: A comparison between laparoscopy and open surgery. J Gastric Cancer [Internet]. Korean Gastric Cancer Association; 2012 [cited 2021 Mar 1];12:243-8. Available from: /pmc/articles/PMC3543975/ 


\section{Tables}

TABLE 1: Case Details: 


\begin{tabular}{|c|c|c|c|}
\hline & PATIENT 1 & PATIENT 2 & PATIENT 3 \\
\hline Age & 62 years & 47 years & 38 years \\
\hline Sex & Female & Male & Male \\
\hline Melena & Yes & Yes & Yes \\
\hline Duration & 2 days & 4 months & 3 years \\
\hline Hematemesis & No & No & No \\
\hline Pain Abdomen & No & No & No \\
\hline Previous History & 1 year back & 2 years back & No \\
\hline Tenderness & No & No & No \\
\hline Lump per abdomen & No & No & No \\
\hline $\begin{array}{l}\text { Hemodynamic } \\
\text { Stability }\end{array}$ & No & Yes & Yes \\
\hline $\begin{array}{l}\text { Blood(PRBC) } \\
\text { Transfusions }\end{array}$ & Yes & Yes & Yes \\
\hline $\begin{array}{l}\text { Number of Blood } \\
\text { Transfusion }\end{array}$ & 4 units & 2 units & 2 units \\
\hline $\mathrm{Hb}$ at admission & 5.6 to $3.9 \mathrm{~g} / \mathrm{dL}$ & $10.7 \mathrm{~g} / \mathrm{dL}$ & $8.9 \mathrm{~g} / \mathrm{dL}$ \\
\hline UGI Endoscopy & Normal & Normal & Normal \\
\hline Colonoscopy & Normal & Normal & Normal \\
\hline \multirow{2}{*}{$\begin{array}{l}\text { Multiphasic CTA } \\
\text { location }\end{array}$} & Mid Jejunal mass & Distal to DJ Flexure & Mid Jejunal mass \\
\hline & $5 \times 4 \times 3.5 \mathrm{~cm}$ & $3.4 \times 2.3 \times 1.6 \mathrm{~cm}$ & $3.5 \times 2.6 \mathrm{~cm}$ \\
\hline Surgery Type & $\begin{array}{l}\text { Open Exploratory } \\
\text { Laparotomy }\end{array}$ & $\begin{array}{l}\text { Open Exploratory } \\
\text { Laparotomy }\end{array}$ & Laparoscopic \\
\hline Elective/Emergency & Emergency & Elective & Elective \\
\hline Indication for Surgery & Unstable & Ongoing bleed & Ongoing bleed \\
\hline Procedure & $\begin{array}{l}\text { Jejunal segmental } \\
\text { resection }\end{array}$ & $\begin{array}{l}\text { Jejunal segmental } \\
\text { resection }\end{array}$ & $\begin{array}{l}\text { Laparoscopic segmental } \\
\text { resection }\end{array}$ \\
\hline \multirow{2}{*}{$\begin{array}{l}\text { Intra Operative } \\
\text { findings }\end{array}$} & $5 \times 5 \mathrm{~cm}$ jejunal mass & $3 \times 2 \mathrm{~cm}$ jejunal mass & $5 \times 5 \mathrm{~cm}$ jejunal mass \\
\hline & Extra and intra mural & Extra and Intramural & Extra and Intramural \\
\hline $\begin{array}{l}\text { Distance from DJ } \\
\text { Flexure }\end{array}$ & $\begin{array}{l}20 \mathrm{~cm} \text { from DJ } \\
\text { flexure }\end{array}$ & $5 \mathrm{~cm}$ from $\mathrm{DJ}$ flexure & $20 \mathrm{~cm}$ from DJ flexure \\
\hline $\begin{array}{l}\text { Post-Operative } \\
\text { Complications }\end{array}$ & Postoperative lleus & None & None \\
\hline
\end{tabular}




\begin{tabular}{|llll|}
\hline Length of Hospital & 8 days & 5 days & 4 days \\
\hline Tumour Type & Jejunal GIST & Jejunal GIST & Jejunal GIST \\
\hline Tumour Size & $4 \times 3 \times 3 \mathrm{~cm}$ & $2.5 \times 2.5 \times 2 \mathrm{~cm}$ & $3 \times 3 \times 5 \mathrm{~cm}$ \\
\hline Nature & Spindle cell & Spindle cell & Spindle cell \\
\hline Mitotic Rate & $<5 / 50$ hpf & No & $>5 / 50$ hpf \\
\hline Tumour Grade & Low Risk & Benign & High Risk \\
\hline Margins & Free of tumour & Free of tumour & Free of tumour \\
\hline Mucosal Breach & Yes & Yes & Yes \\
\hline Serosal Breach & No & No & No \\
\hline CD 117/c-KIT & Positive & Positive & Positive \\
\hline DoG1 & Positive & & Positive \\
\hline S-100 & Negative & & Negative \\
\hline Ki 67 & $<15 \%$ & & $>15 \%$ \\
\hline Follow Up & $\begin{array}{l}12 \text { months Lost to } \\
\text { follow up }\end{array}$ & Asymptomatic & 18 months, \\
\hline
\end{tabular}

Figures 


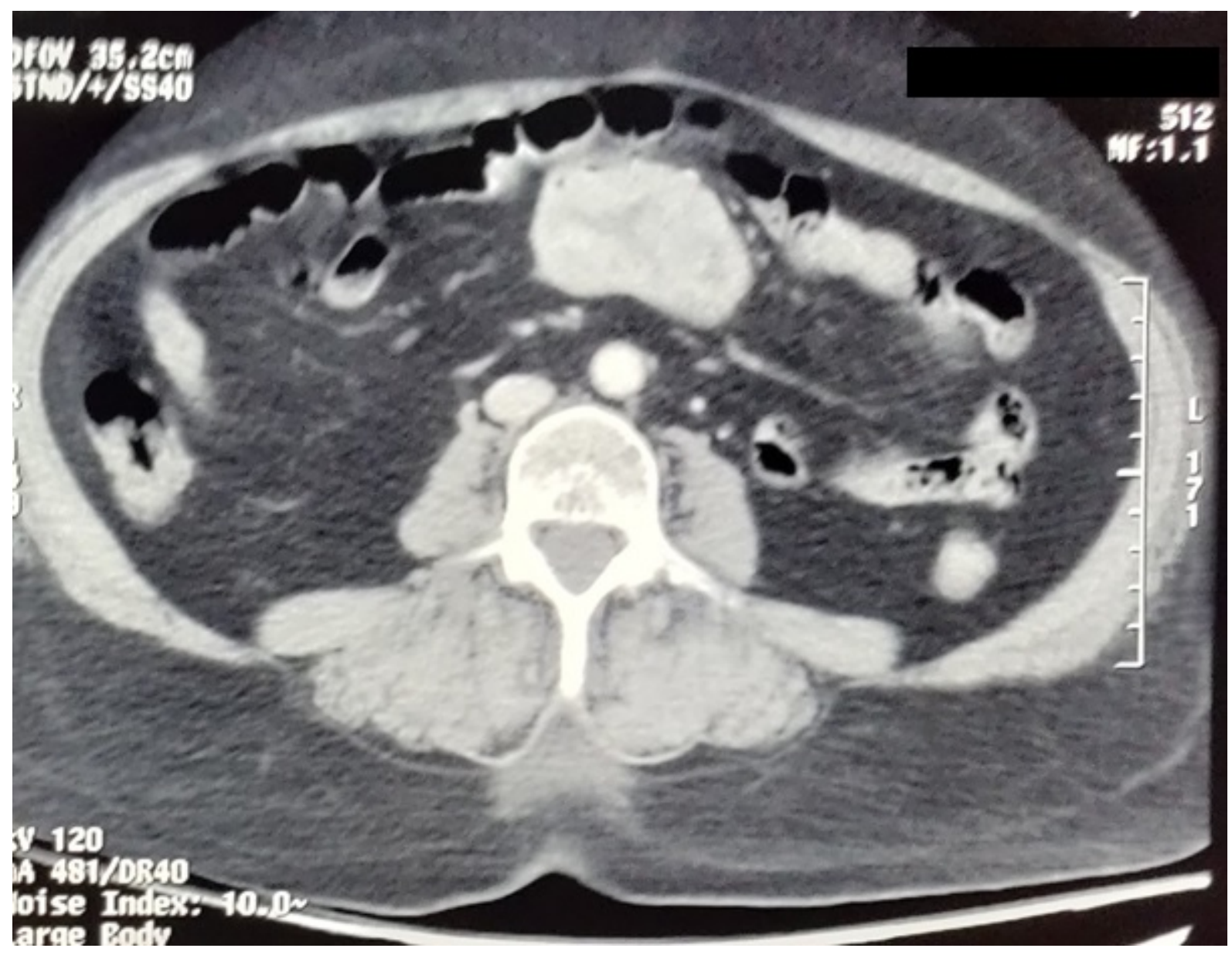

Figure 1

Multiphasic CTA showing heterogenous hypodense hypervascular mass in jejunum without contrast extravasation. 


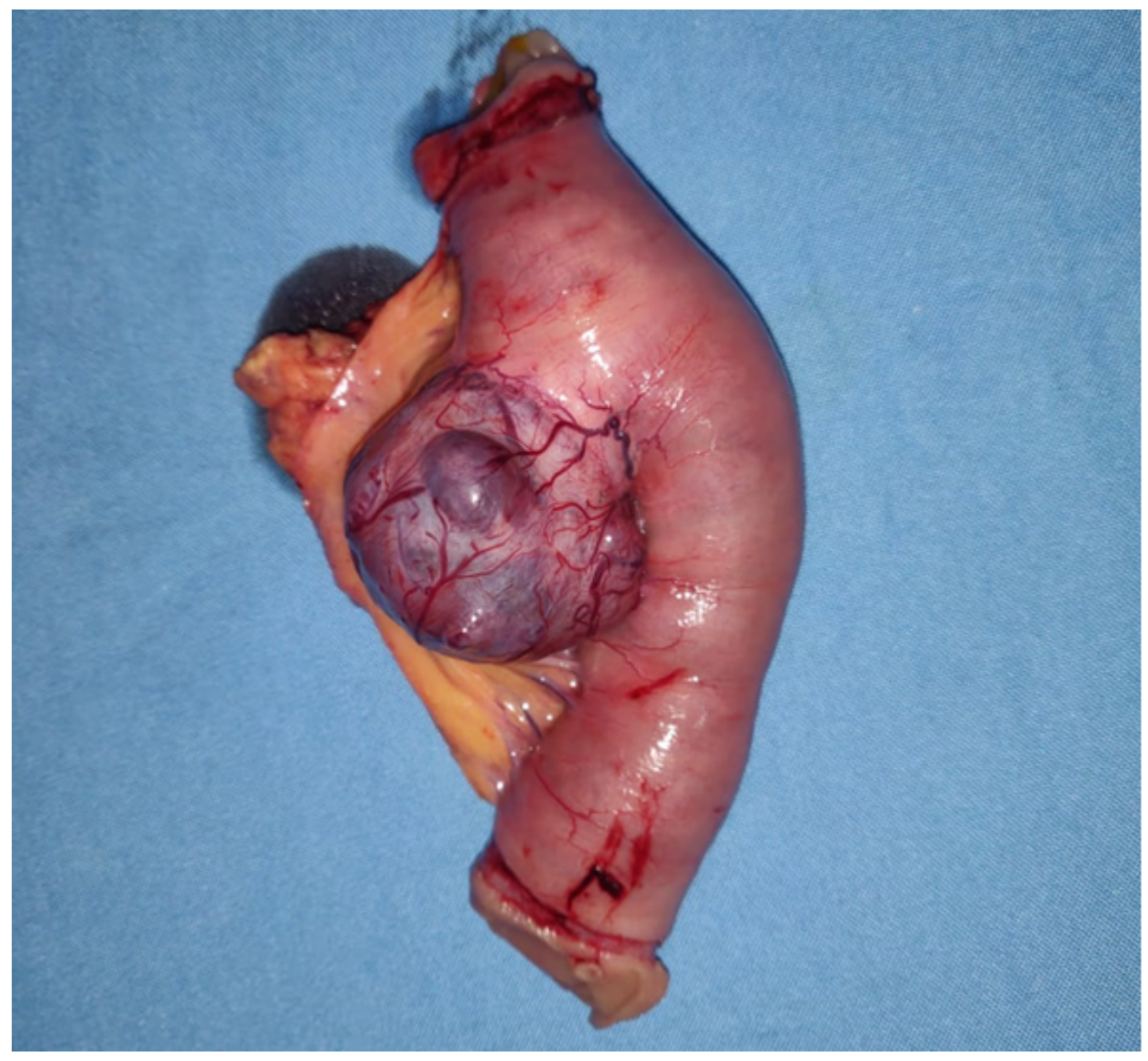

\section{Figure 2}

Resected jejunal GIST segment with adequate free margins. Tumour mass found arising from mesenteric border causing acute massive overt GI bleeding. 


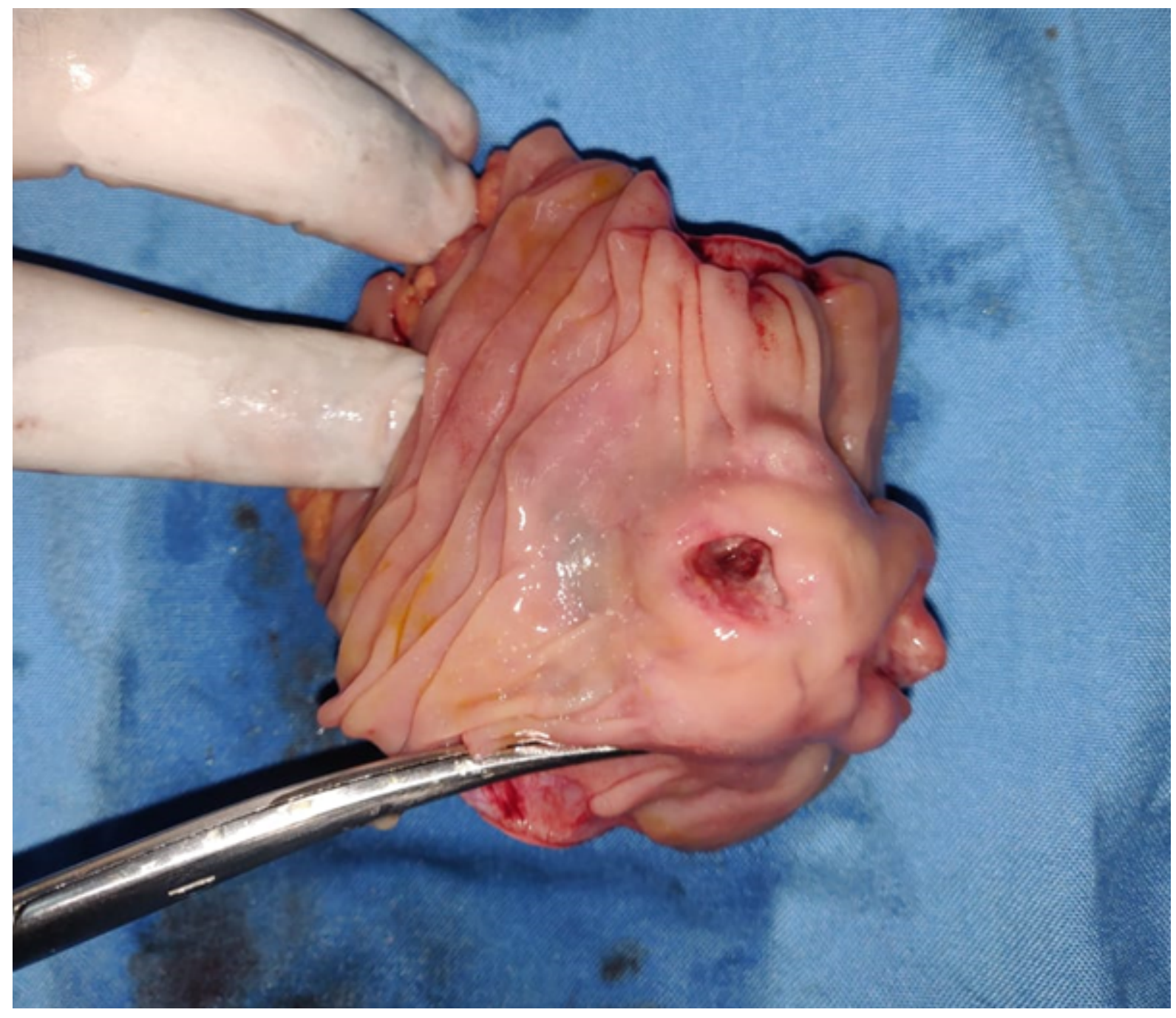

\section{Figure 3}

Cut section of resected jejunal GIST. Mucosal ulceration found at the summit of tumour intraluminally. 


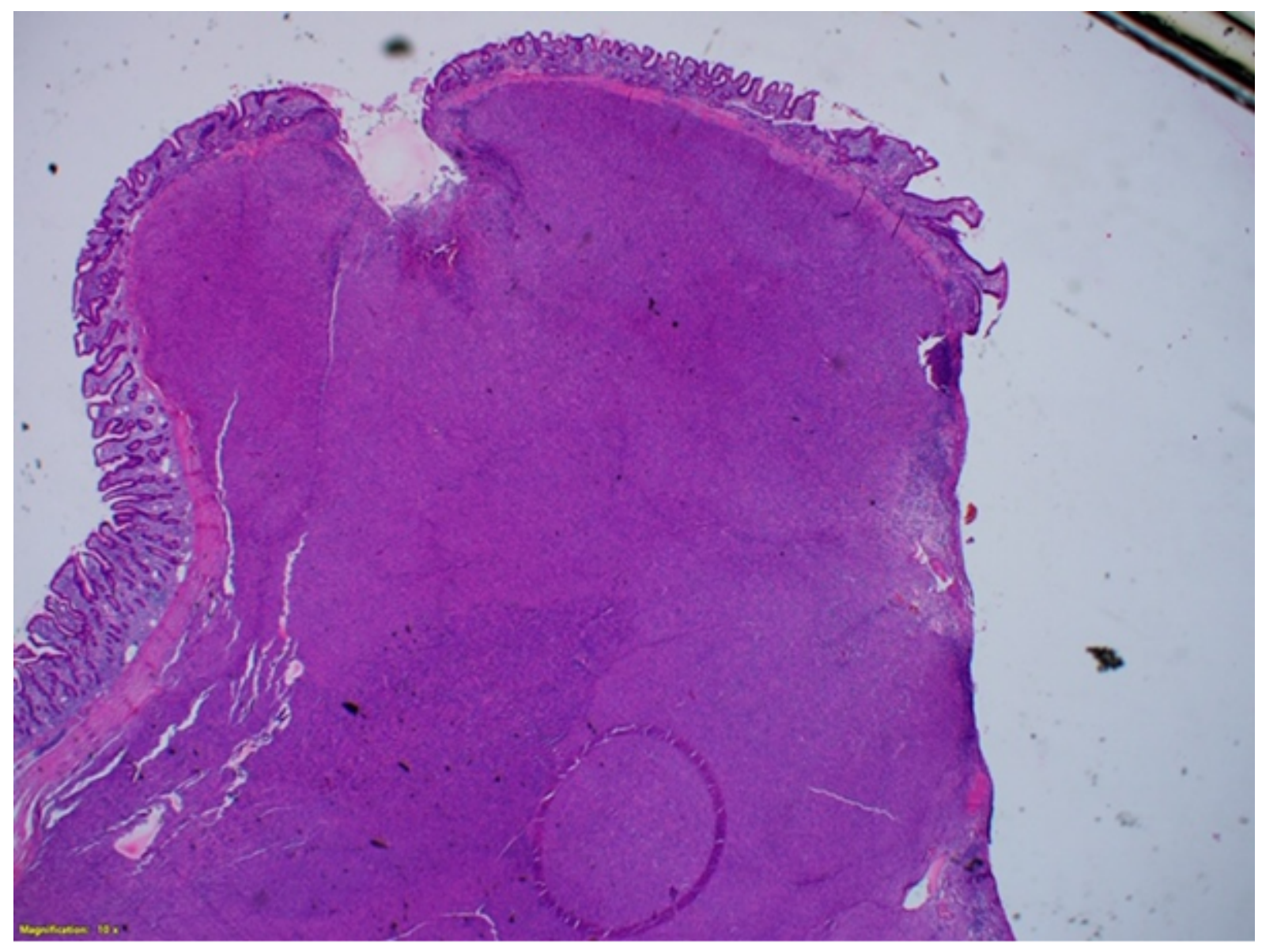

\section{Figure 4}

Histopathological cut section showing focal ulceration in well circumscribed tumor 

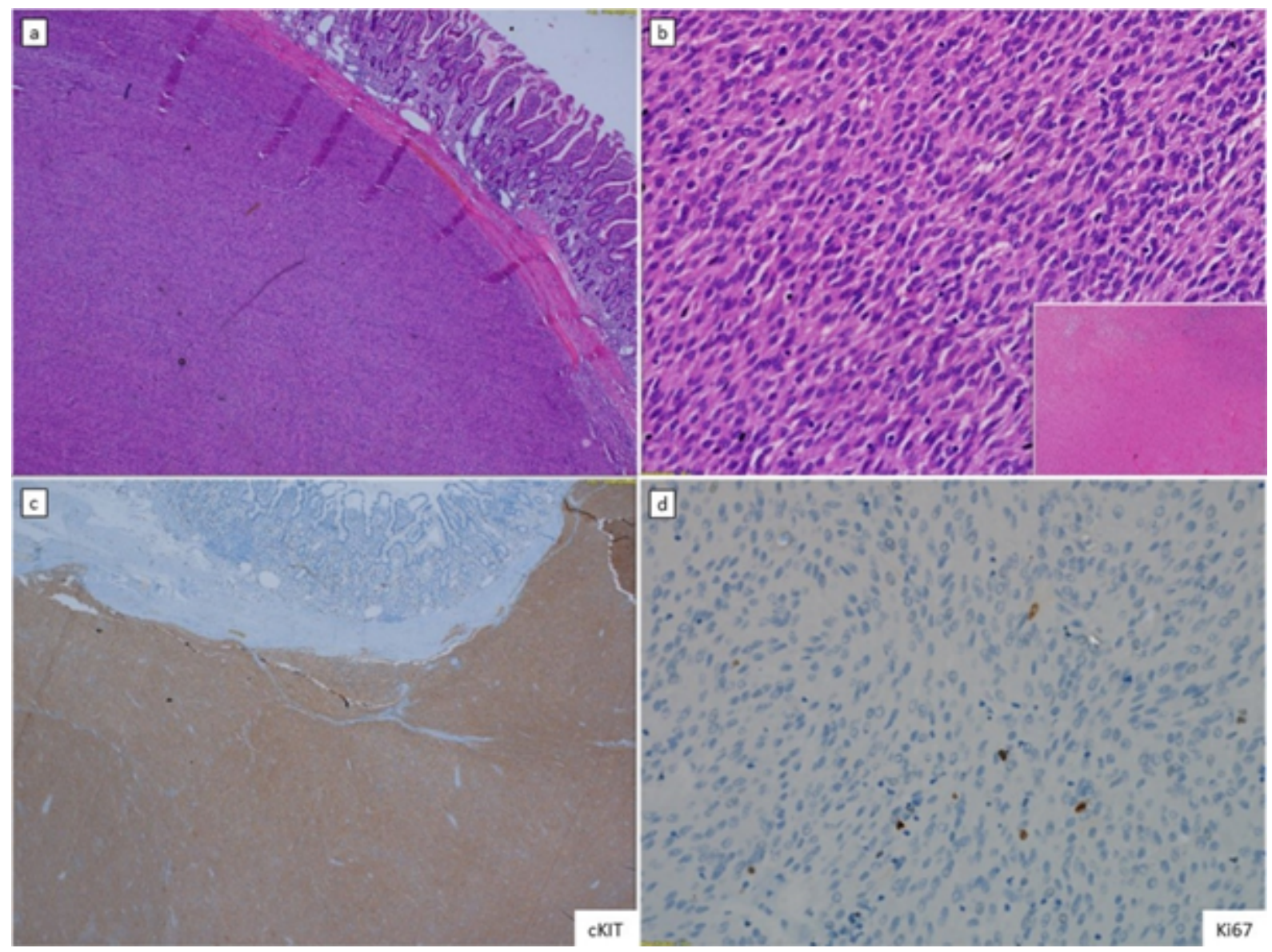

\section{Figure 5}

a, b. Histopathological section showing circumscribed tumor comprised of monomorphic spindle shaped cells (inset shows necrosis) (200x, 400x Hematoxylin and eosin) c. IHC staining of the tumor is diffusely positive for ckit (CD117), 400x DAAB chromogen d. IHC staining with low ki67 index, 400x DAAB chromogen 